\title{
A TECHNIQUE FOR MEASURING X-RAY PHOTOGRAPHS OF THE CARDIAC AREAS OF DOGS
}

\author{
BY HAROLD J. STEWART \\ (From the Hospital of the Rockefeller Institute for Medical Research, New York, N. Y.)
}

(Received for publication July 16, 1926)

It is often important in the study of problems of the circulation to be able to determine what effect an experimental procedure has on the size of the heart of the animal under investigation. For this reason we have developed and adapted a technique for obtaining $\mathrm{x}$-ray photographs of the dog's heart, so that successive records are comparable as to the size of the shadow cast by the heart. The method for obtaining the area of the heart shadow is the one commonly in use as devised by Levy (1).

\section{TECHNIQUE}

Position of the dog. The exposures are made in the antero-posterior position with the dog horizontal. The dog lies on an animal board especially constructed for this purpose. That portion of the board, about 20 by 20 inches, which corresponds to the portion of the dog's chest, is cut out and replaced by a thin sheet of aluminum, below which the cassette carrying the $x$-ray film is placed. The aluminum is used because it cuts out fewer rays than the wood. On each side of the animal board at the level of the chest a right angle upright which is adjustable is attached in order to support the dog. After the dog has been placed on the board straight and without rotation, the uprights can be brought close to the dog's chest and screwed in place (fig. 1). It is necessary to hold the dog's head in place.

$X$-ray technique. The plates are taken at a distance of 2 meters, with an exposure of, on the average, $\frac{1}{8}$ second. Dogs weighing more than $18 \mathrm{kgm}$. require a slightly longer exposure. The exposure is made at the height of inspiration, the short exposure time being necessary because the dogs breathe rapidly. To obtain sharp pictures 


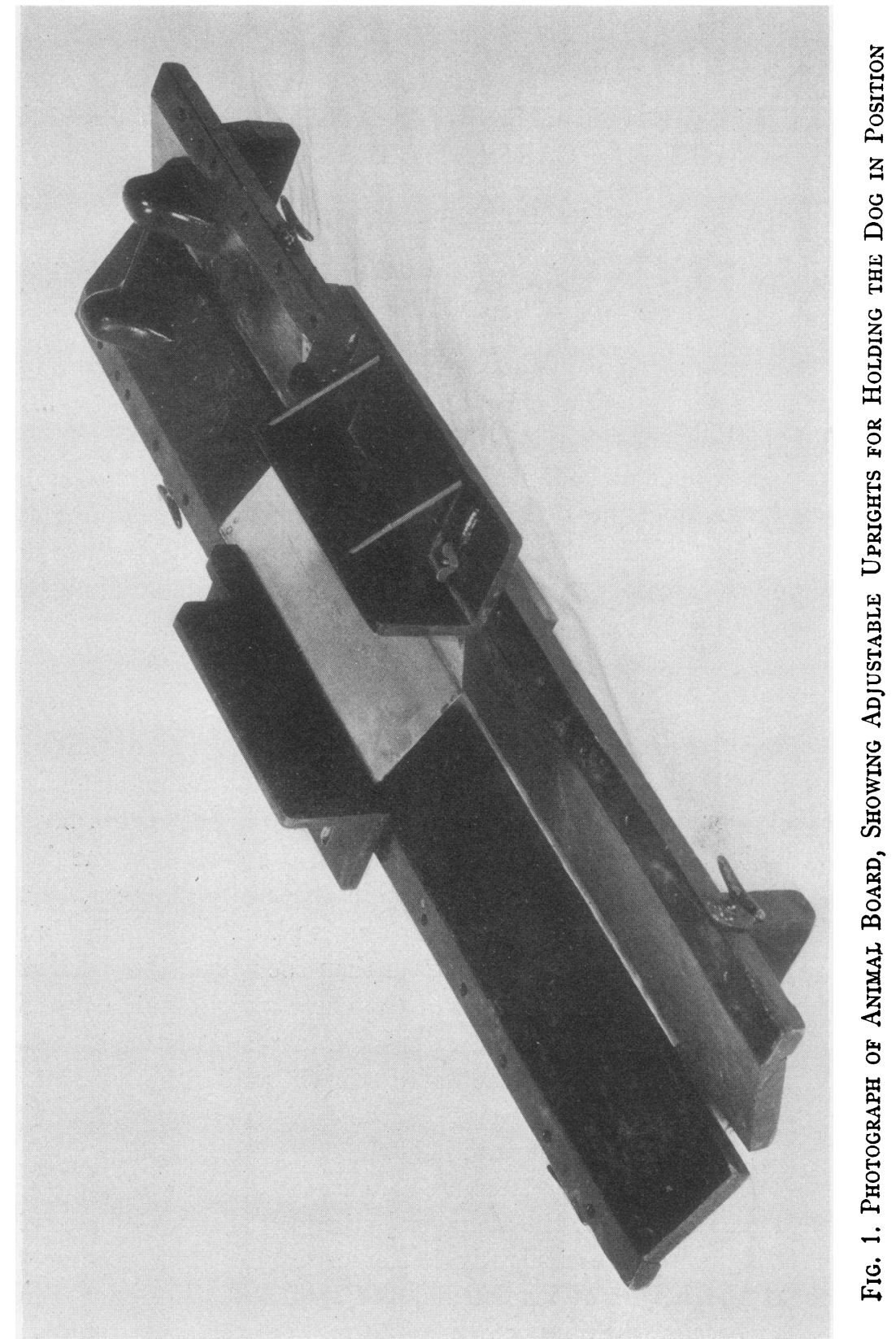


with this short exposure time, we use a spark gap of 9 inches and a 50 milliampere current, with super speed film. ${ }^{1}$ This technique gives

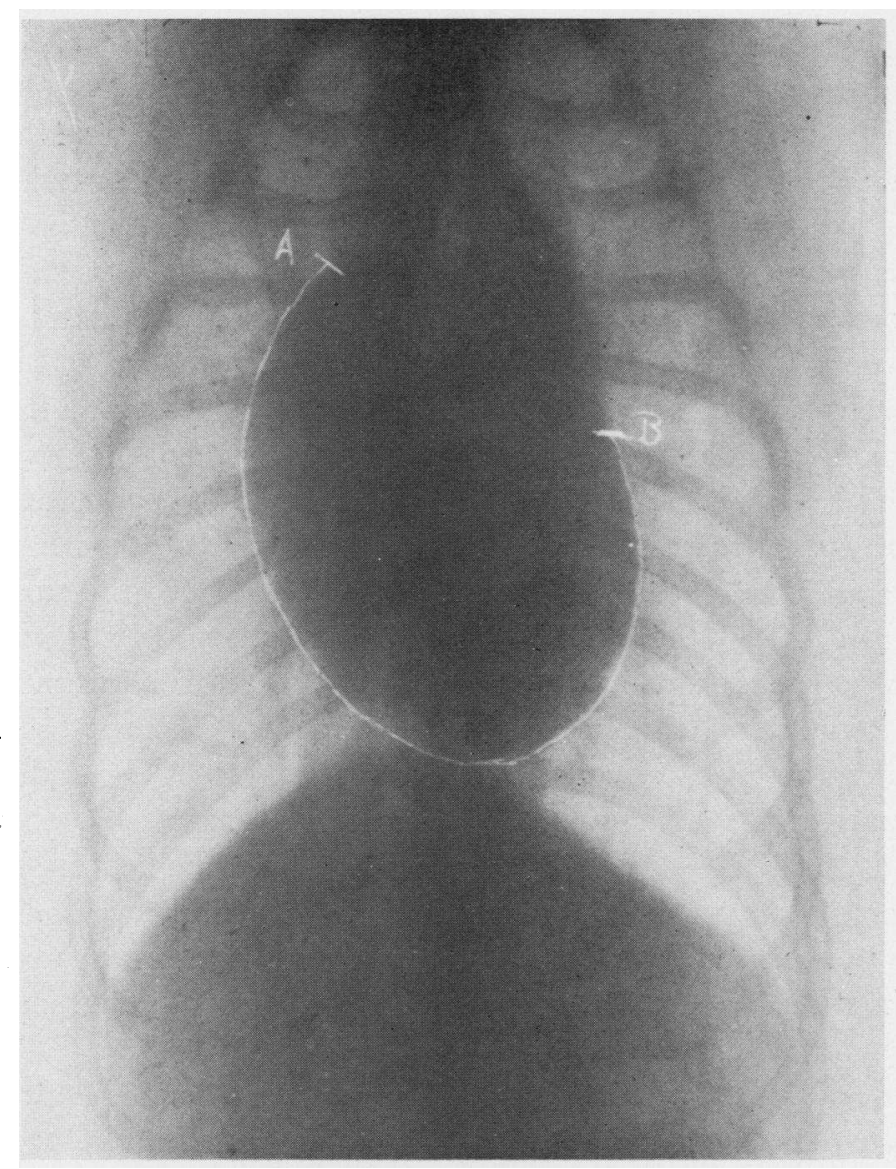

Fig. 2. (Reduced to One-half). X-Ray of Dog's Heart Obtained by the Author's Technique Showing Points $A$ and $B$ and the Heart OUtLined With a Soft Crayon

a sharp definition of the heart shadow without blurring of the rib shadows, which is so often seen when dogs breathe during the exposure. Measurement of the heart area. In the photograph the apex of the

${ }^{1}$ Eastman superspeed duplitized films used with French screens in cassettes. 
heart is usually found a little above the diaphragm or at most barely touches it, so that this part of the heart's contour and the ventricular borders can be easily outlined. It is necessary however to complete the contour of the heart at the base; in order to do this two points are located. On the right, one point is found where the shadow of the right auricle passes into the shadow of the great vessels, this is point $(A)$ (fig. 2). On the left there is usually an indentation where the left ventricular shadow passes into the left auricular shadow, and this is the second point $(B)$. Beginning at $(A)$ the heart shadow is outlined on the film with a soft crayon down to the apex and from the apex up to $(B)$. These lines are then traced on a sheet of paper. Between the points $(A)$ and $(B)$ the outline is completed in the following manner. With compasses the distance between points $(A)$ and $(B)$ is measured, and with this distance as a radius and with $(A)$ as the centre, an arc of a circle is described, and then with $(B)$ as a centre and the same radius, another arc is described intersecting the first arc. With the point of intersection of these two arcs as the centre and the same radius, an arc is described between $(A)$ and $(B)$, completing the heart outline (Levy). The area so formed includes the right ventricle, left ventricle, part of the right auricle and part of the left auricle. Since the area measured in this way is used as the basis of comparison with the area of the heart's shadow at a later time it is necessary only that the area measured includes the same portion of the heart. The area outlined is measured with a planimeter, ${ }^{2}$ two tracings being made; the two readings may differ by not more than $0.5 \mathrm{sq}$. $\mathrm{cm}$.

Protocols. Two types of experiments were carried out. In the first the dog was removed from the board after the photograph was taken and was then put back, when a second one was made. It was found in four experiments that the greatest variation from the first

${ }^{2}$ A convenient method of quickly measuring the heart area is as follows. An unexposed x-ray film, 14 by 17 inches, is developed washed and dried. The four corners are then fixed to a drawing board with thumb tacks. The sheet of paper with the tracing of the heart is slipped under the cleared film and the heart outline measured with a planimeter. The wheel of the planimeter glides easily over the surface of the film. 
record in a large number of photographs was less than 3 per cent (table 1).

In the second type of experiment the variation in the measurements of the heart area over a more prolonged period of time was ascertained. Four normal dogs were $x$-rayed every day for 8 days and the heart areas measured. In addition to this observation, the dog's weights were recorded (table 2). The heart area of the first record of each dog was represented as 100 per cent and the succeeding heart areas were calculated as percentages of this area. The weights were treated in a similar way. The greatest variation in heart area was found in $\operatorname{dog} 49$ on the seventh day, when the heart area was 104.9

TABLE 1

Heart areas of normal dogs with a short time interval between successive photographs

\begin{tabular}{|c|c|c|c|c|}
\hline Dog number & Date & Area & Per cent of first area & Variation \\
\hline 71 & $\begin{array}{c}1922 \\
\text { October } 25\end{array}$ & $\begin{array}{l}\text { sq. cm. } \\
54.25 \\
53.95\end{array}$ & $\begin{array}{r}\text { per cent } \\
100.0 \\
99.4\end{array}$ & $\begin{array}{c}\text { per cent } \\
0.6\end{array}$ \\
\hline 75 & October 26 & $\begin{array}{l}54.65 \\
55.60\end{array}$ & $\begin{array}{l}100.0 \\
101.5\end{array}$ & 1.5 \\
\hline 76 & October 27 & $\begin{array}{l}52.50 \\
52.00\end{array}$ & $\begin{array}{r}100.0 \\
99.0\end{array}$ & 1.0 \\
\hline 77 & November 6 & $\begin{array}{l}55.75 \\
56.93\end{array}$ & $\begin{array}{l}100.0 \\
102.1\end{array}$ & 2.1 \\
\hline
\end{tabular}

per cent (table 2) of its original area, with a variation of 4.9 per cent. Dog 66 showed a negative variation of 4.5 per cent. The total variation in dog 66 was 5.5 per cent (between 95.5 and 101.0 per cent); and in dog 49 it was 5.3 per cent (between 99.6 and 104.9 per cent); and in dogs 67 and 75 the variation was even smaller. In figure 3 we have plotted the heart area and body weight percentages which are tabulated (columns 4 and 6, table 2) to show graphically the variation for each of the 4 dogs. In figure 4 the heart area percentages of the 4 dogs are combined in a single chart to show the grouping of the points about the base line. The body weights are treated in a 
similar manner. The greatest variation seen was 5 per cent greater or 5 per cent less than the original heart area, and although in any

TABLE 2

Heart areas and weights of normal dogs over a period of 8 days

\begin{tabular}{|c|c|c|c|c|c|c|}
\hline $\begin{array}{c}\text { Dog } \\
\text { number }\end{array}$ & Date & Weight & $\begin{array}{l}\text { Per cent } \\
\text { of first weight } \\
\text { given }\end{array}$ & Heart area & $\begin{array}{l}\text { Per cent } \\
\text { of first heart } \\
\text { area }\end{array}$ & $\begin{array}{c}\text { Difference } \\
\text { between highest } \\
\text { and lowest } \\
\text { heart area }\end{array}$ \\
\hline & 1923 & kilos & per cent & $s q . \mathrm{cm}$. & per cent & per cent \\
\hline \multirow[t]{7}{*}{49} & May 11 & 18.28 & 100.0 & 63.65 & 100.0 & \\
\hline & May 12 & 18.33 & 100.3 & 65.40 & 102.7 & \\
\hline & May 14 & 18.00 & 98.5 & 64.55 & 101.4 & \\
\hline & May 15 & 18.75 & 102.6 & 63.30 & 99.6 & 5.3 \\
\hline & May 16 & 18.00 & 98.5 & 65.55 & 102.9 & \\
\hline & May 17 & 17.90 & 97.9 & 66.80 & 104.9 & \\
\hline & May 18 & 17.75 & 97.1 & 64.70 & 101.6 & \\
\hline \multirow[t]{7}{*}{66} & May 11 & 18.50 & 100.0 & 60.18 & 100.0 & \\
\hline & May 12 & 18.00 & 93.7 & 60.68 & 100.8 & \\
\hline & May 14 & 17.80 & 96.1 & 59.00 & 98.0 & \\
\hline & May 15 & 18.55 & 100.2 & 60.30 & 100.1 & 5.5 \\
\hline & May 16 & 17.50 & 94.6 & 57.50 & 95.5 & \\
\hline & May 17 & 17.75 & 95.9 & 60.90 & 101.0 & . \\
\hline & May 18 & 17.30 & 93.5 & 60.58 & 100.6 & \\
\hline \multirow[t]{8}{*}{67} & May 11 & 17.28 & 100.0 & 48.75 & 100.0 & \\
\hline & May 12 & 17.05 & 98.7 & 48.50 & 99.5 & \\
\hline & May 14 & 16.80 & 97.2 & 48.40 & 99.2 & \\
\hline & May 15 & 17.75 & 102.7 & 50.50 & 103.6 & \\
\hline & May 16 & 17.30 & 100.1 & 50.15 & 102.8 & 4.6 \\
\hline & May 17 & 17.15 & 99.2 & 50.20 & 102.9 & \\
\hline & May 18 & 17.05 & 98.7 & 50.60 & 103.8 & \\
\hline & & & & 50.15 & 102.8 & \\
\hline \multirow[t]{8}{*}{75} & May 11 & 19.08 & 100.0 & 60.30 & 100.0 & \\
\hline & May 12 & 18.78 & 98.4 & 60.50 & 100.3 & \\
\hline & May 14 & 18.75 & 98.3 & 59.63 & 98.8 & \\
\hline & May 15 & 19.20 & 100.6 & 62.60 & 103.6 & \\
\hline & May 16 & 18.50 & 96.9 & 60.50 & 100.3 & 4.9 \\
\hline & May 17 & 18.55 & 97.2 & 60.45 & 100.2 & \\
\hline & May 18 & 18.50 & 96.9 & 62.58 & 103.7 & \\
\hline & & & & 62.33 & 103.3 & \\
\hline
\end{tabular}

one dog the variation did not extend to this maximum figure in both directions we have accepted a range of 10 per cent as the normal 
variation, thus including the normal variation in the size of the heart and the errors involved in getting the dogs in the same position and in measuring the area with the planimeter. This is the same variation

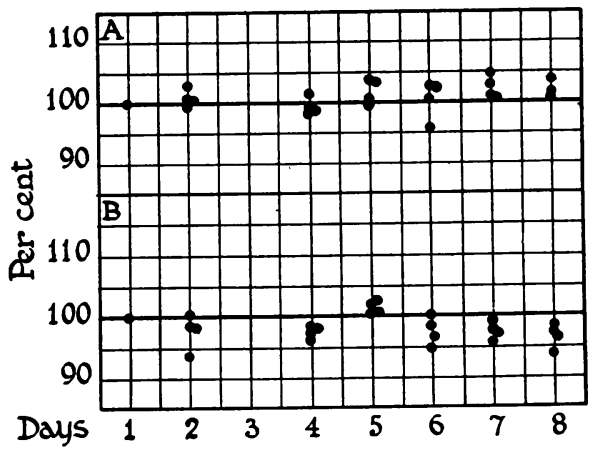

Fig. 3. Percentage Changes in Heart Area and Body Weight of 4 Normal Dogs over a Period of 8 Days

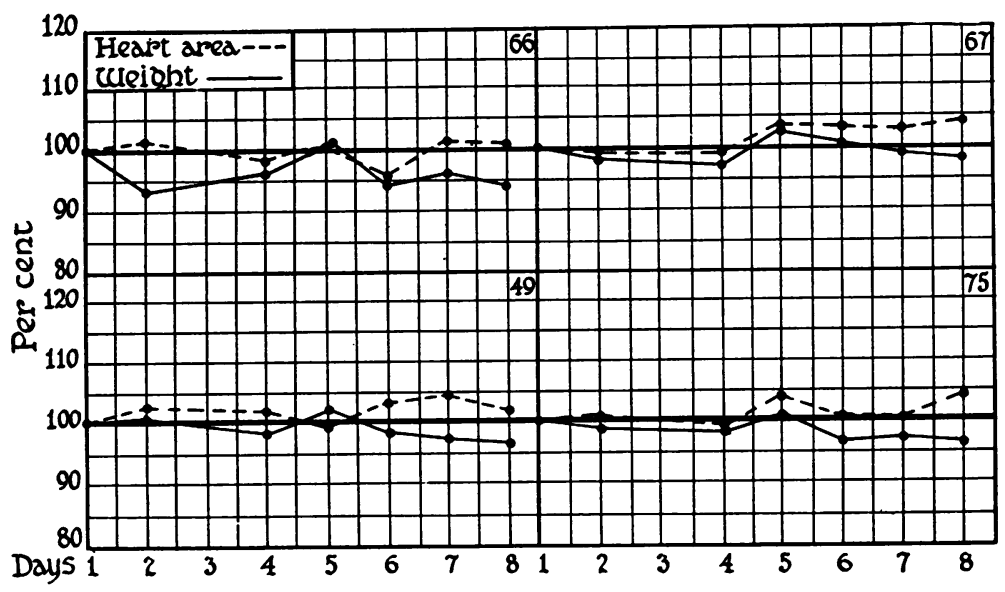

Fig. 4. Percentage Changes of 4 Normal Dogs Combined into One Chart to Show the Deviation from the InItial Body Weights $(B)$ AND Héart Areas $(A)$ which are Represented as 100 Per Cent

which Levy found in measuring the shadows of normal human hearts. During the period of observations there was no significant change in the weights of the dogs. 


\section{SUMMARY}

1. A technique is described for obtaining and measuring $\mathrm{x}$-ray photographs of dog hearts.

2. A variation greater than 10 per cent was not obtained in normal dogs over a period of 8 days. A variation greater than this can be interpreted as a real change in the size of the heart.

3. The variation that occurred in photographs made on the same day was less than 3 per cent.

\section{BIBLIOGRAPHY}

1. Levy, R. L.: Arch. Int. Med., 1923, xxxii, 359. The Size of the Heart in Pneumonia. 